\title{
Tumor stress, cell death and the ensuing immune response
}

\author{
E Ullrich $^{1,2}$, M Bonmort $^{1,2,5}$, G Mignot $^{1,2,5}$, G Kroemer $^{1,3,5}$ and L Zitvogel $\left.\right|^{\star, 1,2,4,5}$
}

A cornucopia of physiological and pathological circumstances including anticancer chemotherapy and radiotherapy can induce cell death. However, the immunological consequences of tumor cell demise have remained largely elusive. The paradigm opposing 'apoptosis versus necrosis' as to their respective immunogenicity does not currently hold to predict long-term immunity. Moreover, the notion that tumor cells may be 'stressed' before death to be recognized by immune cells deserves to be underlined. 'Eat-me', 'danger' and 'killing' signals released by stressed tumor under the pressure of cytotoxic compounds may serve as links between the chemotherapy-elicited response of tumor cells and subsequent immune responses. This review will summarize the state-of-the-art of cancer immunity and describe how tumor cell death dictates the links between innate and acquired immunity.

Cell Death and Differentiation (2008) 15, 21-28; doi:10.1038/sj.cdd.4402266; published online 9 November 2007

\section{Antitumoral Immune Response and Immunosubversion}

The comprehension of natural immune prevention and immune responses to cancer has advanced during the last decades. In 1863, Rudolf Virchow observed 'leucoreticulair infiltrates' in cancer tissues and proposed for the first time a relation of chronic inflammation and tumorigenesis (reviewed by Balkwill et al. ${ }^{1,2}$ ). In 1909, Paul Ehrlich developed the fundamental hypothesis that the immune system could control cancer development. ${ }^{3}$ About 50 years later, the seminal work brought up by Burnet and Thomas supported the concept of tumor immunosurveillance. ${ }^{4,5}$ Later, gene targeting, ${ }^{6}$ transgenic mouse technologies ${ }^{7}$ and highly specific neutralizing monoclonal antibodies targeting particular immune components ${ }^{8}$ have allowed to formally identify the key components of anticancer immune responses.

It is now recognized that the immune system exerts three primary roles for the prevention of tumor outgrowth. First, by suppressing viral infection, the immune system contributes to protecting the host against virus-induced tumors. Second, the immune system interferes with the establishment of chronic inflammation-induced tumorigenesis by regulating pathogeninduced inflammatory processes. ${ }^{2}$ Third, the immune system identifies and destroys precancerous and cancerous lesions expressing tumor-specific antigens or molecular determinants induced by cellular stress. This process can cause the elimination of tumors at the early stage or, alternatively, 'edit' the immunogenic phenotypes of tumors that eventually form in immunocompetent hosts (reviewed in Dunn et al. ${ }^{9}$ ). Indeed, tumors induced in immunodeficient mice are often rejected when they are transplanted to immunocompetent mice, presumably because they have not been 'edited' by the immune system.

Tumors evoke mechanisms to escape immunosurveillance on the basis of genetic mutations and phenotypic changes. Hanahan and Weinberg established six hallmarks of cancer that encompass limitless proliferation, avoidance of cell death, autonomy from growth factors, ignorance of growth-inhibitory signals, provision of angiogenic signals and tissue invasion. ${ }^{10}$ In addition, tumor-induced tolerance might be considered as the seventh hallmark of tumorigenesis. ${ }^{11}$ What are then the possible strategies to reverse or counterbalance tumorinduced immune tolerance? Here, we will discuss that some types of tumor cell death or stress may tip the host-tumor balance towards the reinforcement of the host defenses and we will focus on the question how tumor cell death can modulate the links between innate and acquired immunity.

\section{Immunogenic versus Non-Immunogenic Cell Death}

Tumorigenesis is characterized by the suppression of cell death programs, leading to the outgrowth of chemo- and radio-therapy resistant tumors. The different cell death

\footnotetext{
${ }^{1}$ Institut Gustave Roussy, Villejuif, France; ${ }^{2}$ INSERM, U805, Villejuif, France; ${ }^{3}$ INSERM, U848, Villejuif, France; ${ }^{4}$ Department of Biotherapy, Center of Clinical Investigation CBT507, Villejuif, France and ${ }^{5}$ Université Paris-Sud, Villejuif, France

*Corresponding author: L Zitvogel, U805 INSERM, and CBT507 Center of Clinical Investigations, Institut Gustave Roussy, 39 rue Camille Desmoulins, 94805 Villejuif, France. Tel: + 33-1-42-11-50-41; Fax: + 33-1-42-11-60-94; E-mail: zitvogel@igr.fr

Keywords: apoptosis; tumor immunity; dendritic cells; NK cells; DAMP; chemotherapy

Abbreviations: Ab, antibody; APC, antigen-presenting cell; ATP, adenosine triphosphate; CTL, cytotoxic T cell; DAMP, danger-associated molecular pattern; DC, dendritic cell; cDC, conventional DC; mDC, myeloid DC; pDC, plasmacytoid DC; HMGB1, high-mobility group box 1; Hsp, heat-shock protein; ICAM, intracellular adhesion molecule; IFN, interferon; IKDC, interferon-producing killer dendritic cell; NK, natural killer cells; NKDC, natural killer dendritic cells; NKT, natural killer T-cells; PAMP, pathogen-associated molecular pattern; Rag $^{-1-}$, loss of function mice for the recombination activation gene; TIL, tumor-infiltrating lymphocytes; TRAIL, TNFrelated apoptosis-inducing ligand; VCAM, vascular cell adhesion molecule

Received 11.7.07; revised 20.9.07; accepted 03.10.07; Edited by G Melino; published online 09.11.07
} 
modalities are described in depth by Tesniere et al. in this issue of CDD. The Nomenclature Committee on Cell Death recommended the classification of cell death relying on morphological aspects to clearly distinguish apoptotic (type 1), autophagic (type 2), necrotic (type 3) cell death and mitotic catastrophe. $^{12}$ Apoptosis is a rapid form of cell death, characterized by the rounding of the cell, retraction of pseudopodes, chromatin condensation (pyknosis), nuclear fragmentation (karrhyorhexis), and plasma membrane blebbing. ${ }^{13}$ In contrast, necrotic cell death is characterized by the swelling of cytoplasm (oncosis) and cytoplasmic organelles leading to the disruption of the plasma membrane. Necrosis is commonly considered as a pathological process that is often associated with local inflammation eventually supporting tumor development. ${ }^{14}$

Conventional textbooks of immunology oversimplify the distinction between apoptotic and necrotic cell death considering apoptosis as physiological, programmed and nonimmunogenic cell death and necrosis as a pathological and so far immunological cell death. ${ }^{15,16}$ However, this view has been challenged over the last 2 years, both in the mouse and in the human system. Virus-induced tumor cell death has been described as immunogenic. ${ }^{17}$ While tumor cell death induced by mitomycin $\mathrm{C}$ (with an apoptotic morphology) or freezethawing (with a necrotic morphology) promoted the maturation of dendritic cells (DC) in vitro, inoculation of dead cells could not protect the host against live tumor challenge. ${ }^{18}$ Moreover, while anthracycline-treated tumor cells (which die with an apoptotic morphology) became highly immunogenic in vivo, destroying the corpuscular nature of anthracycline-derived apoptotic bodies by freeze-thawing or hypoosmotic shock could abolish the immunogenicity of anthracycline-killed cells. $^{18}$

\section{Inducers of Immunogenic Cell Death}

Many anticancer compounds directly affect the effector or regulatory arms of tumor immunity (reviewed $\mathrm{in}^{19}$ ) and/or can promote 'an immunogenic cell death'. For instance, gemcitabine is a nucleoside analog that is frequently used to treat nonsmall cell lung, breast and pancreatic cancers. The effects of gemcitabine in modulating antigen-specific antitumor immune responses have been investigated using a murine tumor cell line overexpressing influenza virus hemagglutinin. Crosspresentation of hemagglutinin tumor antigens to $\mathrm{MHC}$ class Iand class II-restricted T cells was enhanced by gemcitabine in tumor-bearing mice. ${ }^{20}$ In addition, gemcitabine could affect the negative arm of antitumor immunity by depressing hemagglutinin-specific $B$ cell responses and myeloid suppressor cells. ${ }^{21}$ Furthermore, gemcitabine could be successfully combined with immunostimulatory compounds (such as CD40-stimulatory antibodies) to yield synergistic antitumor effects $^{22,23}$

Another hint that successful chemotherapy could be associated with improved antigen-specific $T$ lymphocyte responses came from the sequential monitoring of ovarian tumor-specific T-cell responses during cisplatin-based chemotherapy in advanced ovarian carcinoma patients. Only patients in remission displayed potent $\mathrm{CD}^{+} \mathrm{T}$-cell responses, whereas patients in progression did not. ${ }^{24}$
As detailed by Tesniere et al. in this issue of CDD, we developed a method to screen for immunogenic cell death inducers. This method was based on the induction of tumor cell apoptosis by a variety of different agents, subcutaneous inoculation of these dying cells in one flank of immunocompetent mice, and final inoculation of live tumor cells in the opposite flank. The absence of tumor growth then was scored as the indication of an immune response induced by dying tumor cells. ${ }^{18}$ We confirmed previous studies demonstrating that anthracyclines and X-rays can induce antitumor immune responses and delineated some of the molecular cues supporting the immunoadjuvant effects of tumor cell death. ${ }^{25}$ We first showed that the host DC-mediated T-cell priming against tumor cells is pivotal for the immunoadjuvant effects of radiotherapy and chemotherapy. The DC/T cell cross-talk relies on two major checkpoints, calreticulin exposure as 'eat me' signal and the release of high mobility group box 1 (HMGB1) as 'danger' signal by dying tumor cells, thus licensing DC for antigen uptake and TLR4-dependent antigen processing, respectively. ${ }^{25,26}$ Only when both the 'eat me' and the 'danger' signals are correctly emitted by dying tumor cells and perceived by DC, an immune response can be elicited. While the translocation of calreticulin from the endoplasmic reticulum to the plasma membrane was an early process, at least in response to anthracyclins and irradiation, ${ }^{26}$ secretion of HMGB1 by tumor cells was found to be a late process commonly observed during necrosis or late apoptosis. ${ }^{25-28}$ The alarmin HMGB1 was found to act on DC, on the TLR4 receptor, which in turn relays to the MyD88 adapter to allow optimal processing of the tumor antigens. ${ }^{25}$ Indeed, defects in TLR4 signaling have been reported in patient cohorts with breast cancer $^{25}$ and alterations in the MyD88 signaling pathways have been described in patients with head and neck tumors. ${ }^{29}$ These defects could be relevant in preventing the immunoadjuvant effects of chemotherapy-induced cell death. $^{25}$

Another example of immunogenic cell death came from human in vitro studies. Bortezomib is a specific inhibitor of $26 \mathrm{~S}$ proteasome which shows clinical activity against several human tumors including myeloma. ${ }^{30}$ Spisek et al. ${ }^{30}$ demonstrated the elective uptake and processing of bortezomibinduced myeloma cells by human monocyte derived-DC in vitro. In their model, neither $\gamma$ - irradiation nor steroids could elicit antimyeloma-specific T cells although both killed tumor cells in vitro. The DC-mediated T-cell activation was independent of exogenous maturation signals. Interestingly, bortezomib-treated myeloma cells exposed heat-shock protein 90 (Hsp90) on the surface of dying cells. The combination of bortezomib and geldanamycin (an inhibitor of Hsp90) increased the yield of tumor cell apoptosis but diminished their immunogenicity, suggesting that Hsp90 is responsible for the bortezomib-induced immunogenicity.

It is noteworthy that many compounds such as steroids, etoposide or irinotecan induced non-immunogenic cell death. ${ }^{30,31}$ It will be interesting to screen all currently used anticancer chemotherapies for their capacity to elicit immunogenic cell death (as determined in vivo in mice) or to induce molecular changes associated with immunogenicity such as calreticulin exposure, Hsp90 exposure, HMGB1 release or yet-to-be discovered markers of immunogenicity. 


\section{Cell Death and the Link Between Innate and Acquired Immunity}

It is well established that adjuvants are required to elicit an efficient immune response following vaccination. One role of an adjuvant is the stimulation of antigen presenting cells (APC). Janeway's extended self versus non self model proposed that immune responses would be triggered by evolutionary distant organisms through a set of pattern recognition receptors that bind to conserved bacterial 'pathogen-associated molecular patterns' (PAMPs). ${ }^{32}$ However, there is evidence that APC would be receptive to endogenous danger signals from distressed, injured or damaged tissues. ${ }^{33}$ Thus, self-tolerance could be overcome by the adjuvant effect of 'damage associated molecular patterns' (DAMPs). Receptors for DAMPs and PAMPs could act as universal stimulator of tissue repair, remodelling and immunity. ${ }^{33}$ Three putative scenarios that dictate the interplay between tumor cells, DAMPs and innate effectors (including APC and T cells) are discussed below.

The classical three-step model. Compelling evidence points to a critical role of the DC-mediated crosspresentation of tumor-associated antigens for an efficient priming of T cells. In mice depleted of DCs, dying tumor cells fail to elicit anticancer immune responses. ${ }^{29,34,35}$ The prevailing model for cross-presentation of tumor antigen by DC relies on a three-step process, where DC are central (Figure 1). First tumor cells are killed, second DC undergo activation and maturation, third tumor antigen is presented by DC to T cells. In the first step, tumor cells are attacked by innate effector cells such as NK, NKT or $\gamma \delta$ T cells (reviewed $\mathrm{in}^{36}$ ) or succumb to cytotoxic chemotherapeutics. Next, the tumor cell death entails several independent events. Dying tumor cells might not only provide tumor antigens to the microenvironment (and in particular to conventional DC (cDC)), but could also generate endogenous danger signals such as calreticulin or HMGB1 that could induce phagocytosis and processing of the phagocytic cargo by
cDC, respectively. ${ }^{26,29}$ In addition, cDC require a full-blown maturation to prime an antigen-specific effector and memory antitumor T-cell response. Following tumor cell killing, innate effectors could promote DC activation, IL-12 production and Th1 polarization. ${ }^{37,38}$

The disadvantage of this three-step process consists in the involvement of multiple different cell types and hence its possible subversion at multiple levels. Except in conditions of exogenous supply of TLR7 agonists where tumor infiltrating $\mathrm{pDC}$ and $\mathrm{CDC}$ gain lytic function ${ }^{39}$ the pivotal $\mathrm{CDC}$ are not capable of killing tumor cells and are quite sensitive to immunosuppressive pathways (reviewed $\mathrm{in}^{40}$ ). However, in some specific conditions, the same cell type may both kill tumor cells and present the antigen, hence unifying the first two steps of the three-step model.

A proposed two-step model. A two-step process could be envisioned in which the same cell would be able to kill tumor targets, to engulf apoptotic debris and to initiate its differentiation towards a bona fide APC that activates T cells in a direct fashion (Figure 2). The first indication that such a hybrid cell might exist comes from Josien and collaborators, ${ }^{41}$ who found that rat splenic DC could exhibit marker of NK cells and kill a paradigmatic NK cell target (YAC-1 cells). Another report described a novel innate effector called 'NK/DC' in the mouse system. ${ }^{42}$ Such 'NK/ DC' were described to unify DC- and NK-cell functions upon exogenous stimuli such as CpG or IL-18. ${ }^{42}$ At retrospect, these effects might be attributed to a subpopulation of a newly characterized cell type that has been baptized as 'Interferon producing killer dendritic cell (IKDC)'. ${ }^{43-46}$ IKDC simultaneously express DC and NK cell markers and have originally been detected in the infiltrate of tumor metastases that regress after treatment with imatinib mesylate and interleukin-2. Unstimulated IKDC are CD11C NK1.1 B220triple positive cells, but negative for class II and costimulatory molecules. A unique characteristic of IKDC is the production of high amounts of interferon- $\gamma$ and the expression of $\mathrm{MHC}$ class II molecules upon tumor cell contact, without that this

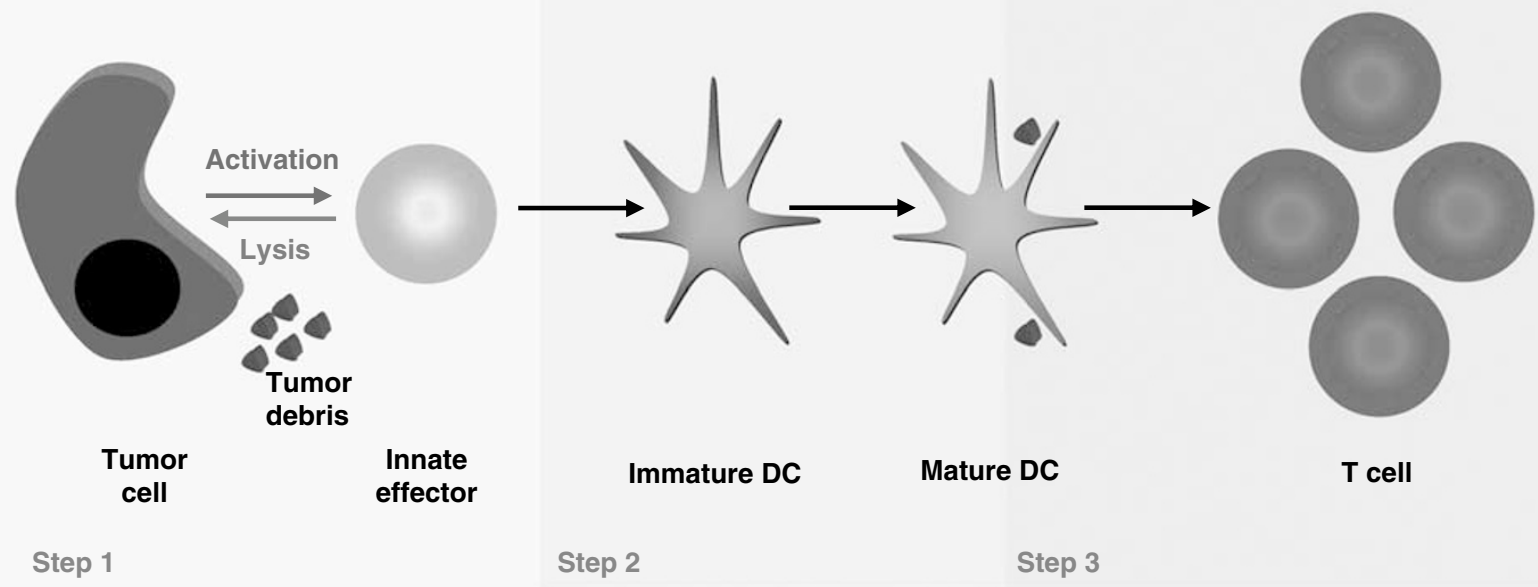

Figure 1 Three-step model from dying tumor cells to acquired immune response. In the first step, tumor cells are attacked by innate effectors (NK, NKT, $\gamma \delta$ T-cell) or directly by cytotoxic agents. In step two, activated cDC will be able to uptake and process tumor antigens and to complete their maturation program. In step three, cDC present tumor antigens to prime an antigen-specific effector and memory T-cell response 


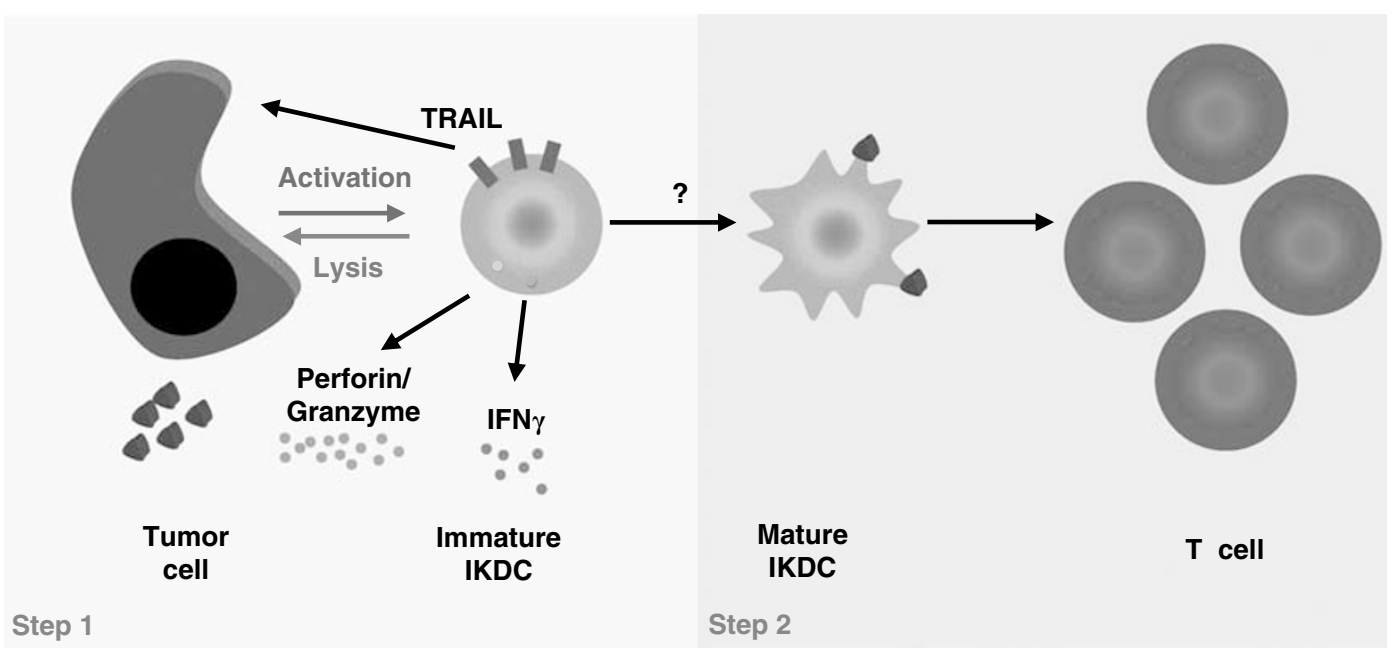

Figure 2. A proposed two-step model. In this mouse model a hybrid effector cell such as an IKDC (or NK/DC) is able to recognize and kill tumor cells, but also to act as antigen-presenting cell leading to antigen-specific T-cell response

stimulation would depend on MHC class I or NKG2D ligands present on the tumor cells. ${ }^{47,48}$ Interestingly, IKDC kill tumor cells in a TRAIL-dependent manner in vitro and in vivo, in conditions where NK cells mostly kill their targets through a perforin/granzyme B pathway. ${ }^{43}$

Tumor licensing by intrinsic or extrinsic cell stress. Tumor cells can be stressed by multiple intrinsic or extrinsic stimuli and both may promote membrane expression or release of 'eat-me signals', 'danger signals', or 'killing signals' that will facilitate immune recognition and final eradication of stressed tumor cells (Figure 3).

Examples of intrinsic stress factors are DNA damage or expression of tumor promoter genes. Aberrant cell proliferation is known to activate the DNA damage response resulting in p53 -dependent cell cycle arrest, senescence or apoptosis. The DNA damage response also induces expression of NKG2D ligands in an ATM or ATR protein kinase-dependent way. ${ }^{49}$ NKG2D is an activating receptor involved in tumor immunosurveillance. It is expressed on NK, NKT, $\gamma \delta$ T cells, as well as resting (in mice) and/or activated (in humans) $\mathrm{CD}^{+}{ }^{+} \mathrm{T}$ cells. Whereas p53 is not required for expression of NKG2D ligands in cells undergoing DNA damage, co-operation between p53 induced-tumor cell senescence and the innate immune system has been recently highlighted. ${ }^{50}$ Restoration of p53 function in established hepatocellular carcinomas led to tumor regression but only in animals bearing an intact immune system. Inflammatory cytokines (such as IL-15 and CSF-1), adhesion molecules (such as ICAM1 and VCAM1) and chemokines (such as CCL2 and CXCL1) were upregulated in liver tumors following p53 reactivation, correlating with the recruitment of neutrophils, macrophages and NK cells into tumor beds and tumor shrinkage. ${ }^{50}$

A link between intrinsic and extrinsic tumor suppressor pathways could be provided by cyclooxygenase-2 (COX-2), a putative tumor promoter. ${ }^{51,52}$ Transgene-enforced overexpression of human COX-2 in mouse mammary glands promoted hyperplasia, dysplasia and transformation into metastatic breast cancer. ${ }^{52}$ Conversely, intestinal polyposis developing in a mouse model of familial adenomatous polyposis could be suppressed by genetically or pharmacologically inhibiting COX-2. ${ }^{51}$ The overproduction of COX-2 and its major product prostaglandin E2 (PGE2) has been detected in many human cancers. It appears plausible that PGE2 acts as an inhibitor of antitumor immune responses. The prostaglandin receptor EP2 plays a key role in PGE2-induced inhibition of DC differentiation, DC function and cancer-associated immunodeficiency. EP2 ${ }^{-1-}$ mice exhibited reduced tumor growth and longer survival times that could be related to the enhanced recruitment of $\mathrm{DC}$ and $\mathrm{T}$ cells into the tumor draining lymph nodes and the generation of effective CTL responses. ${ }^{53}$

Extrinsic factors of tumor cell stress are cell death inducers such as chemotherapy or radiotherapy, but also effector immune cells of the innate or acquired immune system (CTL, NK, NKT, $\gamma \delta$ T-cells). We will detail recently described pathways following extrinsic cell stress, but do not claim to give a complete overview of this rapidly developing field.

As mentioned above, ecto-CRT is an early post-translational regulatory signal induced by anthracyclines, X-rays, ${ }^{26}$ and oxaliplatin (Ghiringhelli $F$, unpublished data) which appears mandatory for the recognition and uptake of dying tumor cells by DC. Interestingly, ecto-CRT exposure can also be triggered by the interaction of tumor cells with activated NK and IKDC (Bonmort M, unpublished data). Killing signals ${ }^{19}$ can be induced by DNA damaging agents (such as 5-FU, cisplatin, X-rays). Killing signals include the increased surface expression of MHC class I, Fas/CD95 and tumor-associated antigenic molecules that facilitate tumor recognition by CTLs (Figure 3). Inhibitors of histone deacetylase can also induce surface expression of NKG2D ligands on tumor cells. ${ }^{54,55}$

We will discuss in greater details the DAMPs that can be emitted by tumor cells following an innate or a therapeutic insult. The seminal work by Shi et al. ${ }^{56}$ revealed that uric acid behaves as an endogenous danger signal that is released by injured cells that activates host DC. Indeed, injured cells rapidly degrade their RNA and DNA, and the liberated purines are converted into uric acid. Uric acid increased markedly after treatment with heat shock, cycloheximide, and emetine 


\section{Tumor licensing}
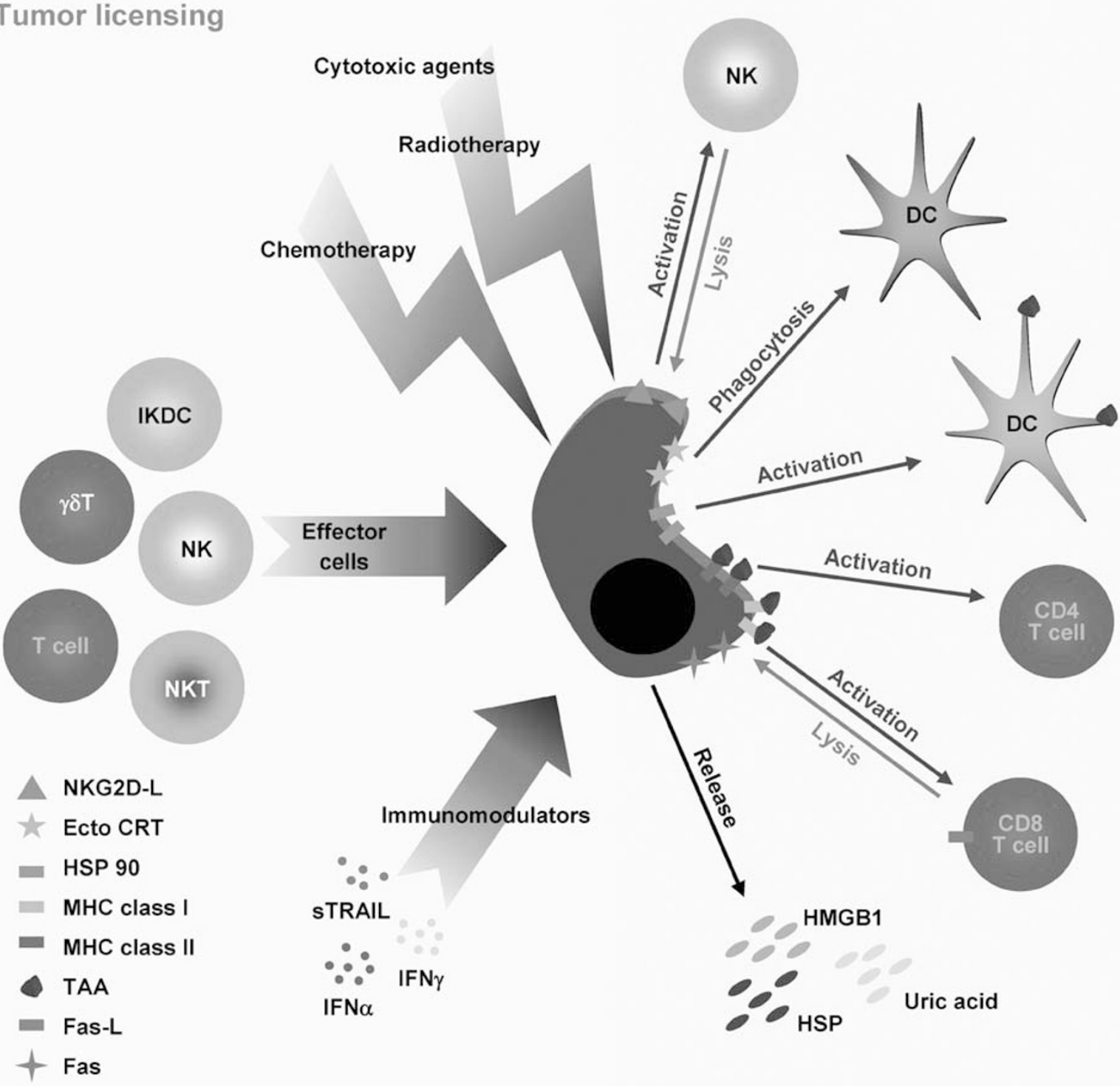

Figure 3 Linking tumor licensing and the immune response. Tumor cells may be attacked by at least three different ways: cytotoxic agents, killer cells (NK, NKT, IKDC, $\gamma \delta$ T-cells, CTL) or immunomodulating agents (TRAIL, IFN $\alpha$, IFN $\gamma$ ). Direct killing activity may be facilitated by various mechanisms 'licensing' tumor cells to express stress or danger signals promoting their recognition by particular effectors. NKG2D-L expression leads to activation of innate immune cells. Ecto-calreticulin (CRT) and Hsp90 expression act as 'eat me' signals and enhance phagocytosis and maturation of DC, respectively. Many chemotherapeutic agents can upregulate MHC class I, class II, tumoractivating antigens (TAA) and Fas/CD95 surface expression on tumor cells, leading to enhanced susceptibility to CTL. Anthracyclines, oxaliplatin, X-Rays but also sTRAIL (and potentially-activated NK and IKDC-expressing TRAIL) can lead to the release of HMGB1 and other 'danger signals' that are mandatory for DC-mediated crosspresentation of apoptotic tumors to T cells. CRT, Calreticulin; DC, Dendritic cell; HMGB1, High mobility group box 1; HSP, Heat-Shock Protein; IFN, Interferon; IKDC, IFNproducing killer DC; NK, Natural killer cell; NKT, Natural killer T-cell; TAA, tumor-associated antigen; TRAIL, TNF-related apoptosis-inducing ligand

in EL4 thymoma cells or after UV irradiation in 3T3 fibroblasts. Uric acid could play the role of adjuvant in combination with soluble antigens and elicited antigen-specific CTL responses in vivo. Inhibition of uric acid production by allopurinol or degradation of uric acid by uricase inhibits the gp120-specific CTL responses elicited through injection of UV-irradiated 3T3 cells coinjected with gp120-coated beads. ${ }^{56}$ Thus, uric acid may act as an obligatory DAMP, at least in some circumstances.

As mentioned above, the high mobility group box 1 (HMGB1) protein is a nuclear constituent loosely bound to chromatin and a mediator of inflammation in the extracellular environment. ${ }^{57}$ Damaged and necrotic cells release HMGB1, and HMGB1 is thought to be responsible for the inflammatory response to cell necrosis. ${ }^{28}$ HMGB1 can either bind to TLR4 or to RAGE (receptor for advanced glycation end products). ${ }^{58,59}$ HMGB1 and RAGE activate plasmacytoid DCs and $B$ cells in response to DNA. ${ }^{60}$ HMGB1 released by necrotic cells is a potent adjuvant in vivo, ${ }^{29,61}$ along with other intracellular components contributing to the adjuvant activity of necrotic supernatants ( $\mathrm{Hsp},{ }^{62}$ uric acid $^{63}$ ). A recent work by Apetoh et al. ${ }^{29}$ supports the notion that the immunoadjuvant 
effects of chemotherapy and radiotherapy-induced cell death rely upon HMGB1 release by tumor cells and TLR4dependent stimulation of host DC. These findings are in line with the role of HMGB1 and TLR4 in liver injury caused by ischemia reperfusion. ${ }^{64}$ Interestingly, HMGB1 can also be released by tumor cells following attack by innate and cognate effectors operating through TRAIL. ${ }^{65}$

DAMPs can promote the specific recruitment of eosinophil or neutrophil granulocytes into tumors. ${ }^{66-68}$ Indeed, HMGB1 release could promote the infiltration of eosinophils into tumor tissue (reviewed $i^{66}$ ). Peripheral blood eosinophilia and tumor-associated tissue eosinophilia are associated with objective responses during immunotherapy with interleukin-2, IL-4, granulocyte-macrophage colony-stimulating factor, and anti CTLA-4. ${ }^{66,69}$ Treatment of tumor cells with irradiation or heat shock followed by membrane disruption was found to promote the release of IL- $1 \alpha$ and the ICE-dependent recruitment of neutrophils towards dying tumor cells. In view of the fact that neutrophils could contribute to the elicitation of longterm antigen-specific CTL responses in melanoma models, ${ }^{70}$ this result suggests that dying tumor cells can induce nonspecific inflammatory reaction that, in turn, may elicit a specific immune response.

Recently, some reports outlined the off target effects of some anticancer compounds in promoting dramatic changes in the chemokine/cytokine tumor microenvironment, leading to the recruitment of tumor antigen-specific $T$ cells into tumor beds. 5,6-dimethylxanthenone-4-acetic acid (DMXAA) is a 'vascular disrupting agent' that is currently used in phase II clinical trials in combination with chemotherapy. ${ }^{71}$ In preclinical tumor models, DMXAA could induce potent antitumor immune responses that contributed to the regression of lung carcinoma and mesothelioma. ${ }^{72}$ DMXAA activated the tumor microenvironment (possibly through the recruitment of the tumor-associated macrophages) that secreted a variety of cytokines and chemokines (including TNF- $\alpha$, IFN-inducible protein-10 (IP-10), IL-6, macrophage inflammatory protein-2, and monocyte chemotactic protein-1) promoting the influx of $\mathrm{CD}^{+}{ }^{+}$T-cells and a CD8 dependent-effector and memory response. ${ }^{72} \mathrm{~A}$ recent report unravelled the mode of action of DMXAA on myeloid cells. DMXAA acts on the TANK-binding kinase 1-interferon (IFN) regulatory factor 3 (IRF-3) signaling pathway. ${ }^{73}$ These findings suggest that the activation of tumor-associated macrophages with DMXAA could be a critical step to promote the recruitment and/or re-activation of tumor-specific $\mathrm{CD}^{+}{ }^{+} \mathrm{T}$ cells. A similar scenario can be proposed for TLR3 agonists. Besides their immunomodulatory effects on myeloid cells, TLR3 agonists could directly target tumor cells. Indeed, a direct proapoptotic activity of TLR3 agonists has been reported on TLR3-expressing breast tumor cell lines. ${ }^{74}$ Moreover, in a mouse model of melanoma and glioma, adjuvant therapy with a TLR3 ligand (Poly I:C stabilized with poly-lysine and carboxymethylcellulose) could trigger the homing of tumor-specific CTLs to tumor beds. In the glioma model, this effect was obtained by the capacity of TLR3 to promote the secretion of IP-10 or and to induce the expression of 'very late antigen-4' (VLA-4, a heterodimer of $\alpha 4$ and $\beta 1$ integrins) on $\mathrm{CTLs}^{75}$ a change that augments the tropism of CTLs for the central nervous system. ${ }^{76}$ In another model, TLR3 agonists could electively break tolerance against a transgenic liver antigen through the secretion of CXCR3 ligands by hepatocytes. ${ }^{77}$ These examples illustrate how TLR ligands can stimulate immune responses.

\section{Counter-Balancing the Immune System}

Microenvironment. The tumor microenvironment is a complex system of many cell types including endothelial cells, their precursors, pericytes, smooth muscle cells, fibroblasts, myofibroblasts, immune effector cells (granulocytes, T-, B-, NK-cells, APC, macrophages) and regulatory immune cells. ${ }^{78}$ Whereas normal stroma can delay or prevent the development of tumors, abnormal stroma built up in a chronic inflammatory context can promote tumorigenesis. Tumor cells have the ability to hijack resident tissue cells for their autonomous proliferation and invasiveness through enforced inflammatory processes. ${ }^{79-82}$ In this proinflammatory milieu, multiple cytokines are released by tumor, stromal or immune cells that can either enhance or inhibit tumor growth. ${ }^{83}$ Briefly, most cytokines that promote inflammation also support tumor proliferation. Interfering with $\mathrm{NF}-\kappa \mathrm{B}$ kinase/NF- $\kappa \mathrm{B}(\mathrm{IKK} / \mathrm{NF}-\kappa \mathrm{B})$ signaling pathway in tumors could counteract the tumor-supporting effects of inflammatory cytokines and confer sensitivity to apoptosis inducers. $^{84,85}$ In contrast, TRAIL, IL-10 and transforming growth factor- $\beta$ interfere with tumor growth ${ }^{83}$ but are also deleterious for antitumor immune responses.

The regulatory arm of the immune system. Tumor cells may employ several mechanisms to escape the immune control, for instance by directly elaborating immunosuppressive pathways or by subverting host DC. The signaling through oncogene products contributes to tumor immune evasion by inhibiting DC differentiation and maturation. ${ }^{86,87}$ In particular, signal transducer and activator of transcription 3 (STAT3) is frequently activated in cancers and mediates immune suppression by inhibiting the expression of proinflammatory chemokines and cytokines required for DC maturation. ${ }^{88}$ In addition, STAT3 activation in tumor cells promotes STAT3 activation in DC and blunts their functions ${ }^{89}$ as well as the migration of immune effectors into tumor beds. Independently, tumor cells could also express PD-L1/B7-H1, B7-H4 or IDO (indolamine 2,3-dioxygenase) which induce anergy or apoptosis of tumor-specific $\mathrm{T}$ cells. $^{90,91}$ It has also been proposed that membrane bound or soluble NKG2D ligands could inhibit the T and the NK cell arm of antitumor immune responses. ${ }^{92-94}$ These pathways might cooperate to promote the emergence of suppressor cells such as regulatory CD4 ${ }^{+} \mathrm{CD} 25^{+} \mathrm{Foxp}^{+}{ }^{+} \mathrm{T}$ cells $\left(\mathrm{T}_{\text {reg }}\right)$, IL-10 producing $\mathrm{Tr} 1$ cells, myeloid suppressor cells, M2 macrophages or tolerogenic DC. ${ }^{40,95}$ Moreover, elevated proportions of $\mathrm{CD}_{2} 5^{+} \mathrm{CD} 4{ }^{+} \mathrm{T}_{\text {reg }}$ among circulating or tumor infiltrating CD4 + T cells have been associated with tumor aggressiveness or progression, ${ }^{40,96,97}$ in models such as NSCLC and ovarian cancer, ${ }^{98,99}$ or pancreas and breast adenocarcinoma. ${ }^{100} \mathrm{~T}_{\text {reg }}$ proliferation could be induced by tolerogenic DC secreting transforming growth factor- $\beta .^{101}$ $\mathrm{T}_{\text {reg }}$ secrete large amounts of IL-10 and transforming growth factor- $\beta$, two cytokines that could participate in the inhibition of $\mathrm{T}$ and NK cell responses. ${ }^{102-104}$ 


\section{Concluding Remarks}

The complete and permanent success of cancer therapy depends on the targeting of all tumor cells including cancer stem cells and micro-metastases. Removal of the tumor (surgery, chemotherapy, radiotherapy) should be escorted by a systemic immune response. We propose that immunogenic chemotherapy' could help unifying two principles in one, tumor cell attack and induction of protective antitumor immunity. The 'eat-me', 'danger' and 'killing' signals delivered by stressed tumor tissues under the pressure of cytotoxic compounds or immunity may serve as links between the chemotherapyelicited response of tumor cells and subsequent immune responses. Future therapeutic strategies may envision multimodal combination therapies that include immunogenic cytotoxic treatment, as well as immunostimulants (or inhibitors of immunosuppressant). It is our intuition that the simultaneous application of agents that exert direct cytotoxic (but immunogenic) effects of tumor cells with agents that favor the immune response would exhibit a synergistic anticancer efficacy. Future clinical studies will tell whether this promise comes true.

Acknowledgements. EU received a fellowship from the Deutsche Forschungsgemeinschaft (DFG). MB has a Poste d'accueil INSERM, GM is supported by the Association pour la Recherche sur le Cancer. This work has also been supported by EU grants (ALLOSTEM, DC THERA, Right, Active p53, TransDeath, ChemoRes), ARC, and Ligue Nationale contre le Cancer (équipes labellisées by GK and LZ).

1. Balkwill F, Mantovani A. Inflammation and cancer: back to Virchow? Lancet 2001; 357 $539-545$

2. Balkwill $F$, Charles KA, Mantovani $A$. Smoldering and polarized inflammation in the initiation and promotion of malignant disease. Cancer Cell 2005; 7: 211-217.

3. Ehrlich P. Über den jetztigen Stand der Karzinomforschung. Ned Tijdschr Geneeskd 1909; 5: 273-290.

4. Burnet M. Cancer; a biological approach. I. The processes of control. Br Med J 1957; 1: 779-786

5. Thomas L. Discussion of cellular and humoral aspects of hypersensitive states. In Lawrence HS (ed) Cellular and Humoral Aspects of the Hypersensitive States. New York Hoeber-Harper, 1959, pp 529-532.

6. van den Broek ME, Kagi D, Ossendorp F, Toes R, Vamvakas S, Lutz WK et al. Decreased tumor surveillance in perforin-deficient mice. J Exp Med 1996; 184 $1781-1790$

7. Shankaran V, Ikeda H, Bruce AT, White JM, Swanson PE, Old LJ et al. IFNgamma and lymphocytes prevent primary tumour development and shape tumour immunogenicity. Nature 2001; 410: 1107-1111.

8. Dighe AS, Richards E, Old LJ, Schreiber RD. Enhanced in vivo growth and resistance to rejection of tumor cells expressing dominant negative IFN gamma receptors. Immunity 1994; 1: 447-456.

9. Dunn GP, Bruce AT, Ikeda H, Old LJ, Schreiber RD. Cancer immunoediting: from immunosurveillance to tumor escape. Nat Immunol 2002; 3: 991-998.

10. Hanahan D, Weinberg RA. The hallmarks of cancer. Cell 2000; 100: 57-70.

11. Zitvogel L, Tesniere A, Kroemer G. Cancer despite immunosurveillance: immunoselection and immunosubversion. Nat Rev Immunol 2006; 6: 715-727.

12. Galluzzi L, Maiuri MC, Vitale I, Zischka $H$, Castedo $M$, Zitvogel $L$ et al. Cell death modalities: classification and pathophysiological implications. Cell Death Differ 2007; 14 1237-1243.

13. Golstein P, Kroemer G. Redundant cell death mechanisms as relics and backups. Cell Death Differ 2005; 12 (Suppl 2): 1490-1496.

14. Vakkila J, Lotze MT. Inflammation and necrosis promote tumour growth. Nat Rev Immunol 2004; 4: 641-648.

15. Bhardwaj N. Harnessing the immune system to treat cancer. J Clin Invest 2007; 117 $1130-1136$

16. Zitvogel L, Casares N, Pequignot MO, Chaput N, Albert ML, Kroemer G. Immune response against dying tumor cells. Adv Immunol 2004; 84: 131-179.

17. Blachere NE, Darnell RB, Albert ML. Apoptotic cells deliver processed antigen to dendritic cells for cross-presentation. PLOS Biol 2005; 3: e185.
18. Casares N, Pequignot MO, Tesniere A, Ghiringhelli F, Roux S, Chaput N et al. Caspasedependent immunogenicity of doxorubicin-induced tumor cell death. J Exp Med 2005; 202: 1691-1701.

19. Zitvogel L, Apetoh L, Ghiringhelli F, Kroemer G. Immunological aspects of anti-cancer chemotherapy. Nat Rev Immunol 2007 (in press)

20. Nowak AK, Robinson BW, Lake RA. Gemcitabine exerts a selective effect on the humoral immune response: implications for combination chemo-immunotherapy. Cancer Res 2002; 62: 2353-2358.

21. Suzuki E, Kapoor V, Jassar AS, Kaiser LR, Albelda SM. Gemcitabine selectively eliminates splenic Gr-1+/CD11b+ myeloid suppressor cells in tumor-bearing animals and enhances antitumor immune activity. Clin Cancer Res 2005; 11: 6713-6721.

22. Broomfield S, Currie A, van der Most RG, Brown M, van BI, Robinson BW et al. Partial, but not complete, tumor-debulking surgery promotes protective antitumor memory when combined with chemotherapy and adjuvant immunotherapy. Cancer Res 2005; 65: 7580-7584

23. Nowak AK, Robinson BW, Lake RA. Synergy between chemotherapy and immunotherapy in the treatment of established murine solid tumors. Cancer Res 2003; 63: $4490-4496$

24. Coleman S, Clayton A, Mason MD, Jasani B, Adams M, Tabi Z. Recovery of CD8+ T-cell function during systemic chemotherapy in advanced ovarian cancer. Cancer Res 2005; 65: 7000-7006

25. Apetoh L, Ghiringhelli F, Tesniere A, Obeid M, Mignot G, Maiuri MC et al. Toll-like receptor 4 -dependent contribution of the immune system to anticancer chemotherapy and radiotherapy. Nat Med 2007; 13: 1050-1059.

26. Obeid M, Tesniere A, Ghiringhelli F, Fimia GM, Apetoh L, Perfettini JL et al. Calreticulin exposure dictates the immunogenicity of cancer cell death. Nat Med 2007; 13: 54-61.

27. Bianchi ME. DAMPs, PAMPs and alarmins: all we need to know about danger. J Leukoc Biol 2007; 81: 1-5

28. Scaffidi P, Misteli T, Bianchi ME. Release of chromatin protein HMGB1 by necrotic cells triggers inflammation. Nature 2002; 418: 191-195.

29. Frenzel H, Hoffmann B, Brocks C, Schlenke P, Pries R, Wollenberg B. Toll-like receptor interference in myeloid dendritic cells through head and neck cancer. Anticancer Res 2006; 26: 4409-4413.

30. Spisek R, Charalambous A, Mazumder A, Vesole DH, Jagannath S, Dhodapkar MV. Bortezomib enhances dendritic cell (DC)-mediated induction of immunity to human myeloma via exposure of cell surface heat shock protein 90 on dying tumor cells: therapeutic implications. Blood 2007; 109: 4839-4845

31. Apetoh L, Ghiringhelli F, Tesniere A, Criollo A, Ortiz C, Lidereau R et al. The interaction between HMGB1 and TLR4 dictates the outcome of anti-cancer chemotherapy and radiotherapy. Immunol Rev 2007 (in press).

32. Janeway Jr CA. How the immune system protects the host from infection. Microbes Infect 2001; 3: 1167-1171.

33. Matzinger P. Friendly and dangerous signals: is the tissue in control? Nat Immunol 2007; 8: $11-13$

34. Zaft T, Sapoznikov A, Krauthgamer R, Littman DR, Jung S. CD11chigh dendritic cell ablation impairs lymphopenia-driven proliferation of naive and memory CD8+ $T$ cells. $\mathrm{J}$ Immunol 2005; 175: 6428-6435.

35. Winau F, Weber S, Sad S, de Diego J, Hoops SL, Breiden B et al. Apoptotic vesicles crossprime CD8T cells and protect against tuberculosis. Immunity 2006; 24: 105-117.

36. Ghiringhelli F, Apetoh L, Housseau F, Kroemer G, Zitvogel L. Links between innate and cognate tumor immunity. Curr Opin Immunol 2007; 19: 224-231.

37. Adam C, King S, Allgeier T, Braumuller H, Luking C, Mysliwietz J et al. DC-NK cell cross talk as a novel CD4+ T-cell-independent pathway for antitumor CTL induction. Blood 2005; 106: 338-344.

38. Mocikat R, Braumuller $\mathrm{H}$, Gumy A, Egeter $\mathrm{O}$, Ziegler $\mathrm{H}$, Reusch $\mathrm{U}$ et al. Natural killer cells activated by MHC class I(low) targets prime dendritic cells to induce protective CD8T cell responses. Immunity 2003; 19: 561-569.

39. Stary G, Bangert C, Tauber M, Strohal R, Kopp T, Stingl G. Tumoricidal activity of TLR7/8activated inflammatory dendritic cells. J Exp Med 2007; 204: 1441-1451.

40. Curiel TJ. $T_{\text {regs }}$ and rethinking cancer immunotherapy. J Clin Invest 2007; 117: 11671174

41. Josien R, Heslan M, Soulillou JP, Cuturi MC. Rat spleen dendritic cells express natural killer cell receptor protein 1 (NKR-P1) and have cytotoxic activity to select targets via a Ca2+-dependent mechanism. J Exp Med 1997; 186: 467-472.

42. Pillarisetty VG, Katz SC, Bleier JI, Shah AB, Dematteo RP. Natural killer dendritic cells have both antigen presenting and lytic function and in response to $\mathrm{CPG}$ produce IFNgamma via autocrine IL-12. J Immunol 2005; 174: 2612-2618.

43. Taieb J, Chaput N, Menard C, Apetoh L, Ullrich E, Bonmort M et al. A novel dendritic cell subset involved in tumor immunosurveillance. Nat Med 2006; 12: 214-219.

44. Shortman K, Villadangos JA. Is it a DC, is it an NK? No, it's an IKDC. Nat Med 2006; 12 : 167-168.

45. Ullrich E, Bonmort M, Mignot G, Chaput N, Taieb J, Menard C et al. Therapy-induced tumor immunosurveillance involves IFN-producing killer dendritic cells. Cancer Res 2007; 67: 851-853.

46. Chan CW, Crafton E, Fan HN, Flook J, Yoshimura K, Skarica M et al. Interferonproducing killer dendritic cells provide a link between innate and adaptive immunity. Nat Med 2006; 12: 207-213. 
47. Vremec D, O'Keeffe $M$, Hochrein $H$, Fuchsberger M, Caminschi I, Lahoud $M$ et al. Production of interferons by dendritic cells, plasmacytoid cells, natural killer cells and interferon-producing killer dendritic cells. Blood 2007; 109: 1165-1173.

48. Bonmort M, Ullrich E, Mignot G, Chaput N, Zitvogel L. IFNgamma is produced by another player of immune responses: IKDC. Biochimie 2007; 89: 872-877.

49. Gasser S, Orsulic S, Brown EJ, Raulet DH. The DNA damage pathway regulates innate immune system ligands of the NKG2D receptor. Nature 2005; 436: 1186-1190.

50. Xue W, Zender L, Miething C, Dickins RA, Hernando E, Krizhanovsky V et al. Senescence and tumour clearance is triggered by p53 restoration in murine liver carcinomas. Nature 2007; 445: 656-660.

51. Oshima M, Dinchuk JE, Kargman SL, Oshima H, Hancock B, Kwong E et al. Suppression of intestinal polyposis in Apc delta716 knockout mice by inhibition of cyclooxygenase 2 (COX-2). Cell 1996; 87: 803-809.

52. Liu CH, Chang SH, Narko K, Trifan OC, Wu MT, Smith E et al. Overexpression of cyclooxygenase-2 is sufficient to induce tumorigenesis in transgenic mice. J Biol Chem 2001; 276: 18563-18569

53. Yang L, Yamagata N, Yadav R, Brandon S, Courtney RL, Morrow JD et al. Cancerassociated immunodeficiency and dendritic cell abnormalities mediated by the prostaglandin EP2 receptor. J Clin Invest 2003; 111: 727-735.

54. Armeanu S, Bitzer M, Lauer UM, Venturelli S, Pathil A, Krusch M et al. Natural killer cellmediated lysis of hepatoma cells via specific induction of NKG2D ligands by the histone deacetylase inhibitor sodium valproate. Cancer Res 2005; 65: 6321-6329.

55. Skov S, Pedersen MT, Andresen L, Straten PT, Woetmann A, Odum N. Cancer cells become susceptible to natural killer cell killing after exposure to histone deacetylase inhibitors due to glycogen synthase kinase-3-dependent expression of MHC class Irelated chain A and B. Cancer Res 2005; 65: 11136-11145.

56. Shi $\mathrm{Y}$, Evans JE, Rock KL. Molecular identification of a danger signal that alerts the immune system to dying cells. Nature 2003; 425: 516-521.

57. Wang $\mathrm{H}$, Yang $\mathrm{H}$, Tracey KJ. Extracellular role of HMGB1 in inflammation and sepsis. $J$ Intern Med 2004; 255: 320-331.

58. Dumitriu IE, Baruah P, Bianchi ME, Manfredi AA, Rovere-Querini P. Requirement of HMGB1 and RAGE for the maturation of human plasmacytoid dendritic cells. Eur $J$ Immunol 2005; 35: 2184-2190.

59. Messmer D, Yang H, Telusma G, Knoll F, Li J, Messmer B et al. High mobility group box protein 1: an endogenous signal for dendritic cell maturation and Th1 polarization. J Immunol 2004; 173: 307-313.

60. Tian J, Avalos AM, Mao SY, Chen B, Senthil K, Wu H et al. Toll-like receptor 9-dependen activation by DNA-containing immune complexes is mediated by HMGB1 and RAGE. Nat Immunol 2007; 8: 487-496.

61. Rovere-Querini $P$, Capobianco A, Scaffidi P, Valentinis B, Catalanotti F, Giazzon M et al HMGB1 is an endogenous immune adjuvant released by necrotic cells. EMBO Rep 2004; 5: $825-830$.

62. Basu S, Binder RJ, Suto R, Anderson KM, Srivastava PK. Necrotic but not apoptotic cell death releases heat shock proteins, which deliver a partial maturation signal to dendritic cells and activate the NF-kappa B pathway. Int Immunol 2000; 12: 1539-1546.

63. Shi Y, Evans JE, Rock KL. Molecular identification of a danger signal that alerts the immune system to dying cells. Nature 2003; 425: 516-521.

64. Tsung A, Sahai R, Tanaka H, Nakao A, Fink MP, Lotze MT et al. The nuclear facto HMGB1 mediates hepatic injury after murine liver ischemia-reperfusion. J Exp Med 2005; 201: 1135-1143.

65. Ito N, Demarco RA, Mailliard RB, Han J, Rabinowich H, Kalinski $\mathrm{P}$ et al. Cytolytic cells induce HMGB1 release from melanoma cell lines. J Leukoc Biol 2007; 81: 75-83.

66. Lotfi R, Lee JJ, Lotze MT. Eosinophilic granulocytes and damage-associated molecular pattern molecules (DAMPs): role in the inflammatory response within tumors. J Immunother 2007; 30: 16-28.

67. Seino K, Kayagaki N, Okumura K, Yagita H. Antitumor effect of locally produced CD95 ligand. Nat Med 1997; 3: 165-170.

68. Cormier SA, Taranova AG, Bedient C, Nguyen T, Protheroe C, Pero R et al. Pivotal Advance: eosinophil infiltration of solid tumors is an early and persistent inflammatory host response. J Leukoc Biol 2006; 79: 1131-1139.

69. Van Oosterhout AJ, Hofstra CL, Shields R, Chan B, Van Al, Jardieu PM et al. Murine CTLA4-IgG treatment inhibits airway eosinophilia and hyper-responsiveness and attenuates $\mathrm{lgE}$ upregulation in a murine model of allergic asthma. Am J Respir Cell Mol Biol 1997; 17: 386-392.

70. Shiratsuchi Y, lyoda T, Tanimoto N, Kegai D, Nagata K, Kobayashi Y. Infiltrating neutrophils induce allo-specific CTL in response to immunization with apoptotic cells via MCP-1 production. J Leukoc Biol 2007; 81: 412-420.

71. Chaplin DJ, Horsman MR, Siemann DW. Current development status of small-molecule vascular disrupting agents. Curr Opin Investig Drugs 2006; 7: 522-528.

72. Jassar AS, Suzuki E, Kapoor V, Sun J, Silverberg MB, Cheung L et al. Activation of tumorassociated macrophages by the vascular disrupting agent 5,6-dimethylxanthenone-4acetic acid induces an effective CD8+ T-cell-mediated antitumor immune response in murine models of lung cancer and mesothelioma. Cancer Res 2005; 65: 11752-11761.

73. Roberts ZJ, Goutagny N, Perera PY, Kato H, Kumar H, Kawai T et al. The chemotherapeutic agent DMXAA potently and specifically activates the TBK1-IRF-3 signaling axis. J Exp Med 2007; 204: 1559-1569.
74. Salaun B, Coste I, Rissoan MC, Lebecque SJ, Renno T. TLR3 can directly trigger apoptosis in human cancer cells. J Immunol 2006; 176: 4894-4901.

75. Zhu X, Nishimura F, Sasaki K, Fujita M, Dusak JE, Eguchi J et al. Toll like receptor-3 ligand poly-ICLC promotes the efficacy of peripheral vaccinations with tumor antigenderived peptide epitopes in murine CNS tumor models. J Transl Med 2007; 5: 10

76. Calzascia T, Berardino-Besson W, Wilmotte R, Masson F, de Tribolet N, Dietrich PY et al. Cutting edge: cross-presentation as a mechanism for efficient recruitment of tumorspecific CTL to the brain. J Immunol 2003; 171: 2187-2191.

77. Lang KS, Georgiev P, Recher M, Navarini AA, Bergthaler A, Heikenwalder M et al. Immunoprivileged status of the liver is controlled by Toll-like receptor 3 signaling. J Clin Invest 2006; 116: 2456-2463.

78. Albini A, Sporn MB. The tumour microenvironment as a target for chemoprevention. Nat Rev Cancer 2007; 7: 139-147.

79. Tlsty TD, Hein PW. Know thy neighbor: stromal cells can contribute oncogenic signals. Curr Opin Genet Dev 2001; 11: 54-59.

80. Elenbaas B, Weinberg RA. Heterotypic signaling between epithelial tumor cells and fibroblasts in carcinoma formation. Exp Cell Res 2001; 264: 169-184

81. Bissell MJ, Radisky D. Putting tumours in context. Nat Rev Cancer 2001; 1: 46-54.

82. Wiseman BS, Werb Z. Stromal effects on mammary gland development and breast cancer. Science 2002; 296: 1046-1049.

83. Lin WW, Karin M. A cytokine-mediated link between innate immunity, inflammation, and cancer. J Clin Invest 2007; 117: 1175-1183.

84. Karin M, Greten FR. NF-kappaB: linking inflammation and immunity to cance development and progression. Nat Rev Immunol 2005; 5: 749-759.

85. Karin M. Nuclear factor-kappaB in cancer development and progression. Nature 2006; 441: $431-436$

86. Vicari AP, Caux C, Trinchieri G. Tumour escape from immune surveillance through dendritic cell inactivation. Semin Cancer Biol 2002; 12: 33-42.

87. Almand B, Resser JR, Lindman B, Nadaf S, Clark JI, Kwon ED et al. Clinical significance of defective dendritic cell differentiation in cancer. Clin Cancer Res 2000; 6: 1755-1766.

88. Wang T, Niu G, Kortylewski M, Burdelya L, Shain K, Zhang S et al. Regulation of the innate and adaptive immune responses by Stat-3 signaling in tumor cells. Nat Med 2004 10: $48-54$.

89. Cheng $\mathrm{F}$, Wang HW, Cuenca A, Huang M, Ghansah T, Brayer J et al. A critical role for Stat3 signaling in immune tolerance. Immunity 2003; 19: 425-436.

90. Curiel TJ, Wei S, Dong H, Alvarez X, Cheng P, Mottram P et al. Blockade of B7-H1 improves myeloid dendritic cell-mediated antitumor immunity. Nat Med 2003; 9: 562-567.

91. Uyttenhove C, Pilotte L, Theate I, Stroobant V, Colau D, Parmentier N et al. Evidence for a tumoral immune resistance mechanism based on tryptophan degradation by indoleamine 2,3-dioxygenase. Nat Med 2003; 9: 1269-1274.

92. Oppenheim DE, Roberts SJ, Clarke SL, Filler R, Lewis JM, Tigelaar RE et al. Sustained localized expression of ligand for the activating NKG2D receptor impairs natura cytotoxicity in vivo and reduces tumor immunosurveillance. Nat Immunol 2005; 6 928-937.

93. Braud VM, Allan DS, O'Callaghan CA, Soderstrom K, D'Andrea A, Ogg GS et al. HLA-E binds to natural killer cell receptors CD94/NKG2A, B and C. Nature 1998; 391 795-799.

94. Wu JD, Higgins LM, Steinle A, Cosman D, Haugk K, Plymate SR. Prevalent expression of the immunostimulatory MHC class I chain-related molecule is counteracted by shedding in prostate cancer. J Clin Invest 2004: 114: 560-568.

95. Zou W. Regulatory T cells, tumour immunity and immunotherapy. Nat Rev Immunol 2006; 6: 295-307.

96. Wang HY, Lee DA, Peng G, Guo Z, Li Y, Kiniwa Y et al. Tumor-specific human CD4+ regulatory $T$ cells and their ligands: implications for immunotherapy. Immunity 2004; 20 107-118.

97. Wang RF. Immune suppression by tumor-specific CD4+ regulatory T-cells in cancer. Semin Cancer Biol 2006; 16: 73-79.

98. Woo EY, Chu CS, Goletz TJ, Schlienger K, Yeh H, Coukos G et al. Regulatory CD4(+)CD25(+) T cells in tumors from patients with early-stage non-small cell lung cancer and late-stage ovarian cancer. Cancer Res 2001; 61: 4766-4772.

99. Curiel TJ, Coukos G, Zou L, Alvarez X, Cheng P, Mottram P et al. Specific recruitment of regulatory $T$ cells in ovarian carcinoma fosters immune privilege and predicts reduced survival. Nat Med 2004; 10: 942-949.

100. Liyanage UK, Moore TT, Joo HG, Tanaka Y, Herrmann V, Doherty G et al. Prevalence of regulatory $T$ cells is increased in peripheral blood and tumor microenvironment of patients with pancreas or breast adenocarcinoma. J Immunol 2002; 169: 2756-2761.

101. Ghiringhelli F, Larmonier N, Schmitt E, Parcellier A, Cathelin D, Garrido C et al. CD4+CD25+ regulatory $T$ cells suppress tumor immunity but are sensitive to cyclophosphamide which allows immunotherapy of established tumors to be curative. Eur J Immunol 2004; 34: 336-344.

102. Ghiringhelli F, Menard C, Terme M, Flament C, Taieb J, Chaput N et al. CD4+CD25+ regulatory $T$ cells inhibit natural killer cell functions in a transforming growth factor-\{beta\}dependent manner. J Exp Med 2005; 202: 1075-1085

103. Smyth MJ, Teng MW, Swann J, Kyparissoudis K, Godfrey DI, Hayakawa Y. CD4+CD25+ $T$ regulatory cells suppress NK cell-mediated immunotherapy of cancer. J Immunol 2006 ; 176: 1582-1587

104. Bach JF. Regulatory T cells under scrutiny. Nat Rev Immunol 2003; 3: 189-198. 